\title{
Medical students' satisfaction on online flipped learning by learning styles
}

\author{
Su Jin Chae
}

Department of Medical Education, Catholic Kwandong University College of Medicine, Incheon, Korea

Purpose: The purpose of this study was to examine the differences in the medical students' satisfaction on online flipped learning by the learning style.

Methods: A total of 42 second-year medical students were participated in this study. As study tools, Felder and Soloman's Index of Learning Styles and the Korean Educational Development Institute's National Assessment of Student Engagement in Learning were utilized. Data analysis was conducted with the Kruskal-Wallis test, a nonparametric statistical method.

Results: Results showed that there were statistically significant differences within active-reflective types and sensing-intuitive types. The active-reflective type has been shown to have statistically significant differences for the three effects of learning, such as problem solving and understanding, active participation, and self-directed learning attitudes. For sensing-intuitive type, active participation showed a significant difference from other effects of learning.

Conclusion: The learning style is an important concept in understanding the diverse ways in which students process and absorb new information. Hence research is needed to conduct successful small group activities through online. In the future, it is necessary to find the factors that can lead to successful online classes in medical schools.

Key Words: Flipped learning, Learning style, Medical student, Medical school

\section{Introduction}

In medical education, the explosive growth of medical knowledge and technology such as artificial intelligence has brought about the need for change in the existing lecture-based teaching structure. Many medical schools are introducing flipped learning for training future health professionals [1].

Flipped learning stems from a constructivist learning theory in which learner-centered education is achieved through collaboration. Many medical schools have introduced flipped learning as a new teaching method to stimulate students' critical thinking and active participation [2]. Flipped learning is a kind of small group activity method in which students independently explore course content online at pre-class and then in class engage in interactions in the form of problem- solving and discussion [3]. Flipped learning has the pedagogical features of encouraging self-directed learning, inquiry learning, and learner-centered learning, which these may be influenced by the personal orientation each
Received: August 4, 2021 • Revised: August 19, 2021 • Accepted: October 17, 2021 Corresponding Author: Sujin Chae (https://orcid.org/0000-0003-3060-8933) Department of Medical Education, International St. Mary' s Hospital, Catholic Kwandong University College of Medicine, 25 Simgok-ro 100beon-gil, Seo-gu, Incheon 22711, Korea Tel: +82.32.290.3882 Fax: +82.32.290.3440 email: edujin@cku.ac.kr
Korean J Med Educ 2021 Dec; 33(4): 405-409 https://doi.org/10.3946/kjme.2021.208 eISSN: 2005-7288

(C) The Korean Society of Medical Education. All rights reserved. This is an open-access article distributed under the terms of the Creative Commons Attribution Non-Commercial License (http:// creativecommons.org/licenses/by-nc/3.0/), which permits unrestricted non-commercial use, distribution, and reproduction in any medium, provided the original work is properly cited. 
individual learner. This study focused on learners' unique learning styles.

A learning style refers to an individual's manner and attitude in acquiring and processing information in learning situations [4]. In a psychological sense, a learning style pertains to the way students concentrate and is a tool for acquiring and processing knowledge, information, and learning experiences. In a cognitive sense, it refers to a tool that shapes perception, processes information, and builds concepts and principles. Learners have different learning styles [5]. Thus, each one uses his/her unique methods to acquire information and comprehend the facts presented.

Over the coronavirus disease 2019 (COVID-19) pandemic, various types of collaborative activities were conducted using synchronous online classes. A typical method is to use Zoom, a video communications application. In the present study, the online flipped learning was done group work during in class time via Zoom. The purpose of this study is to investigate students' satisfaction with online flipped learning via Zoom by medical students' learning styles and to explore implication for medical education.

\section{Methods}

\section{Participants}

This study was conducted on 44 second-year medical students who took the reproductive integrated course in 2020 at the Catholic Kwandong University College of Medicine. All participants were informed about the study and their informed consent was obtained. Excluding the surveys of two students who were excluded due to insincere responses, the surveys of 42 students ( 25 males and 17 females) were analyzed.

\section{Measures}

\section{1) Index of Learning Styles Questionnaire}

The study used Felder and Soloman's Index of Learning Styles (ILS) Questionnaire to evaluate the students' learning style preferences in four dimensions based on the Felder-Silverman model [5]. The four learning styles, namely, active or reflective, sensing or intuitive, visual or verbal, and sequential or global. The ILS questionnaire consists of 44 questions. The scale of each learning style ranged from -11 to 11 in the four different dimensions. Cronbach's $\alpha$ was 0.911 for ILS's inter-consistency.

\section{2) Satisfaction Questionnaire}

Satisfaction Questionnaire related to students' class activities were based on the Korean Educational Development Institute's National Assessment of Student Engagement in Learning (NASEL) questionnaire [6], conducted by selecting and customizing it to fit medical school classes. In Table 1, each item was measured on a 5 -point Likert scale from "strongly disagree" (1 point) to "strongly agree" (5 points). The Cronbach $\alpha$ was 0.935 , for NASEL inter-consistency.

\begin{tabular}{ll}
\hline Table 1. Satisfaction Questions \\
\hline \multicolumn{1}{c}{ Category } \\
\hline Problem solving and understanding & 1. Repeated learning of the course contents improves my understanding. \\
& 2. I can find solutions or alternatives to a problem. \\
Active participation & 3. I do not doze off or fall asleep during class. \\
Self-directed learning attitudes & 4. I participate in discussions. \\
& 5. It is interesting, and it motivates my learning. \\
\end{tabular}




\section{Data analysis}

The ILS and satisfaction data were analyzed using the PASW SPSS ver. 18.0 (SPSS Inc., Chicago, USA) statistics software. Because the number of participants and the size of each learning style group were small $(n<50)$, a nonparametric method, the Kruskal-Wallis test was used.

\section{Ethics approval and consent to participate}

This study was approved by the institutional review board of the International St. Mary's Hospital, Catholic Kwandong University College of Medicine (IRB approval no., IS21QISI034).

\section{Results}

Student satisfaction depending on learning style is summarized in Table 2. Problem solving and understanding, active participation, and self-directed learning attitude significantly presented online flipped learning in the active-reflective learning style, with chi-square scores of $\chi^{2}=8.18(\mathrm{p}=0.01), \chi^{2}=5.45 \quad(\mathrm{p}=0.05)$, and $\chi^{2}$ $=8.79(\mathrm{p}=0.01)$, respectively. For sensing-intuitive type, active participation showed a significant difference from other effects of learning $\left(\chi^{2}=4.20, \mathrm{p}<0.05\right)$. For visualverbal and sequential-global types, no statistically sig- nificant difference was discovered among the satisfaction's scores of learning style.

\section{Discussion}

During the COVID-19 pandemic, various educational institutions executed their academic curricula online via asynchronous and synchronous classes. Medical schools in Korea were no exception. This study explored medical students' satisfaction with online flipped learning by learning styles. According to the study result, it has been revealed that there are differences in satisfaction of flipped learning by learning styles. There were statistically significant differences within active-reflective types and sensing-intuitive types.

These results are consistent with Abidin et al. [7], wherein active-type students showed significantly higher scores of class satisfaction than reflective-typed students. Likewise, Chae [8] reported that active-type students had higher satisfaction with problem-based learning (PBL). In contrast, Hur and Kim [9] found that reflective-type students were more satisfied with their academic achievement and PBL classes than their active-type colleagues. Kim et al. [10] also showed that reflective-type students had higher satisfaction's score than those of active-type students. The researcher thought that these different results would be related to

\begin{tabular}{|c|c|c|c|c|c|c|c|c|c|c|c|c|}
\hline \multirow{3}{*}{ Contents } & \multicolumn{12}{|c|}{ Learning styles } \\
\hline & \multicolumn{3}{|c|}{ Active-reflective } & \multicolumn{3}{|c|}{ Sensing-intuitive } & \multicolumn{3}{|c|}{ Visual-verbal } & \multicolumn{3}{|c|}{ Sequential-global } \\
\hline & Mean $\pm S D$ & $\chi^{2}$ & p-value & Mean $\pm S D$ & $\chi^{2}$ & p-value & Mean $\pm S D$ & $\chi^{2}$ & $p$-value & Mean $\pm S D$ & $\chi^{2}$ & p-value \\
\hline $\begin{array}{l}\text { Problem solving and } \\
\text { understanding }\end{array}$ & $3.95 \pm 0.696$ & 8.18 & $0.004^{* *}$ & $3.95 \pm 0.696$ & 0.50 & 0.477 & $3.95 \pm 0.696$ & 1.81 & 0.178 & $3.95 \pm 0.696$ & 0.64 & 0.422 \\
\hline Active participation & $4.28 \pm 0.596$ & 5.45 & $0.019^{*}$ & $4.28 \pm 0.596$ & 4.20 & $0.040^{*}$ & $4.28 \pm 0.596$ & 3.27 & 0.070 & $4.28 \pm 0.596$ & 0.42 & 0.516 \\
\hline $\begin{array}{l}\text { Self-directed } \\
\text { learning attitude }\end{array}$ & $3.95 \pm 0.763$ & 8.79 & $0.003^{* *}$ & $3.95 \pm 0.763$ & 0.33 & 0.565 & $3.95 \pm 0.763$ & 3.27 & 0.070 & $3.95 \pm 0.7631$ & 0.30 & 0.582 \\
\hline
\end{tabular}

SD: Standard deviation.

${ }^{*} p<0.05 .{ }^{* *} p<0.01$. 
the characteristics of online learning, especially synchronous learning through zoom. In other words, because online flipped learning is conducted through real-time videoconferencing in class, there is almost no time for self-reflection. Thus, this method of synchronous learning would be more advantageous to quick-witted and active-type students.

Also, the results of the present study support that of El-Bishouty et al. [4]. They claim that the online environment is suitable for sensory-visual learners and advantageous for facilitating teacher and student communication. The current study reported that sensory-visual participants actively engaged in discussions without dozing off or doing anything else during flipped learning.

This result has a limitation in that it is difficult to generalize because of the limited study sample.. Therefore, follow-up research involving medical students at different year levels from different medical schools in Korea is needed. Over the past 20-30 years, medical education has attained remarkable qualitative improvements and reforms in terms of educational methods. Especially due to the COVID-19 pandemic, online learning using information technology has accelerated, and new concepts of educational methods, including flipped learning, are being implemented. In the future, it is necessary to find the factors that can lead to successful online classes in medical schools.

In the educational sector, learning style is an important concept in understanding the diverse ways in which students process and absorb new information. Therefore, it is paramount that research on learning styles of students be continuously performed, not only for integrating learning process and facilitating knowledge acquirement but also for helping individual students reach their full potential and targeted goals.

\section{ORCID:}

Sujin Chae: https://orcid.org/0000-0003-3060-8933

Acknowledgements: None.

Funding: None.

Conflicts of interest: No potential conflict of interest relevant to this article was reported.

Author contributions: All work was done by Sujin Chae.

\section{References}

1. Mehta NB, Hull AL, Young JB, Stoller JK. Just imagine: new paradigms for medical education. Acad Med. 2013;88(10):1418-1423.

2. Angadi NB, Kavi A, Shetty K, Hashilkar NK Effectiveness of flipped classroom as a teaching-learning method among undergraduate medical students: an interventional study. J Educ Health Promot. 2019;8:211.

3. Lage MJ, Platt GJ, Treglia M. Inverting the classroom: a gateway to creating an inclusive learning environment. J Econo Educ. 2000;31(1):30-43.

4. El-Bishouty MM, Aldraiweesh A, Alturki U, et al. Use of Felder and Silverman learning style model for online course design. Educ Technol Res Dev. 2019;67(1): 161-177.

5. Felder RM, Soloman BA. Learning styles and strategies. Raleigh, USA: North Carolina State University; 1993.

6. Korean Educational Development Institute. National survey of student engagement in Korean universities. Jincheon, Korea: Korean Educational Development Institute; 2010.

7. Abidin MJ, Rezaee AA, Abdullah HN, Singh KK. Learning styles and overall academic achievement in a specific educational system. Int J Humanit Soc Sci. 2011;1(10):143-152.

8. Chae SJ. Effects of problem-based learning by learning 
style in medical education. Korean J Med Educ. 2012; 24(4):347-351.

9. Hur Y, Kim S. Different outcomes of active and reflective students in problem-based learning. Med Teach. 2007; 29(1):el8-e21.

10. Kim M, Kim S, Lee J, Ahn D, Lee Y. Characteristics of medical students' learning styles and their relationships to GPA. Korean J Med Educ. 2006;18(2):133-140. 